\title{
Diametral tensile strength of composite resins submitted to different activation techniques
}

\section{Resistência à tração diametral de compósitos resinosos submetidos a diferentes técnicas de ativação}

\author{
Denise Sá Maia Casselli* \\ Claudia Cia Worschech* \\ Luis Alexandre Maffei Sartini Paulillo** \\ Carlos Tadeu dos Santos Dias***
}

\begin{abstract}
The aim of this study was to evaluate the diametral tensile strength (DTS) of composite resins submitted to different curing techniques. Four composite resins were tested in this study: Targis (Ivoclar), Solidex (Shofu), Charisma (Heraeus-Kulzer) and Filtek Z250 (3M Espe). Sixty-four cylindrical specimens were prepared and divided into eight groups according to each polymerization technique $(n=8)$. The indirect composite resins (Targis and Solidex) were polymerized with their respective curing systems (Targis Power and EDG-lux); Charisma and Filtek Z250 were light-cured with conventional polymerization (halogen light) and additionally, with post-curing systems. Specimens were stored in artificial saliva at $37^{\circ} \mathrm{C}$ for one week. DTS tests were performed in a Universal Testing Machine $(0.5 \mathrm{~mm} / \mathrm{min})$. The data were statistically analyzed by ANOVA and Duncan tests. The results were $(\mathrm{MPa})$ : Z250/EDG-lux: 69.04a ; Z250/Targis Power: 68.57ª Z250/conventional polymerization: 60.75 ${ }^{\text {b }}$ Charisma/Targis

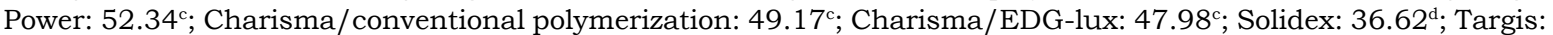
$32.86^{\mathrm{d}}$. The results reveal that the post-cured $Z 250$ composite resin showed the highest DTS means. Charisma composite presented no significant differences when activation techniques were compared. Direct composite resins presented higher DTS values than indirect resins.
\end{abstract}

DESCRIPTORS: Composite resins; Physical properties; Tensile strength.

RESUMO: O objetivo do trabalho foi avaliar a resistência à tração diametral (DTS) de compósitos submetidos a diferentes técnicas de polimerização. Foram testados quatro compósitos neste estudo: Targis (Ivoclar), Solidex (Shofu), Charisma (Heraeus-Kulzer) e Filtek Z250 (3M Espe). Foram confeccionados 64 corpos-de-prova cilíndricos, que foram divididos em 8 grupos de acordo com a técnica de polimerização $(n=8)$. Os compósitos indiretos (Targis e Solidex) foram polimerizados com seus respectivos sistemas de ativação (Targis Power e EDG-lux); Charisma e Filtek Z250 foram fotoativados com polimerização convencional (luz halógena) e, adicionalmente, com sistemas de polimerização adicional. Os corpos-de-prova foram armazenados em saliva artificial a $37^{\circ} \mathrm{C}$ por uma semana. Ensaio de DTS foi realizado em Máquina Universal de Ensaios Instron (0,5 mm/ min). Os dados foram analisados estatisticamente pelos testes ANOVA e Duncan. Os resultados foram (MPa): Z250/EDG-lux: 69,04a; Z250/Targis Power: 68,57a; Z250/polimerização convencional: 60,75 ; Charisma/Targis Power: 52,34c; Charisma/polimeriza-

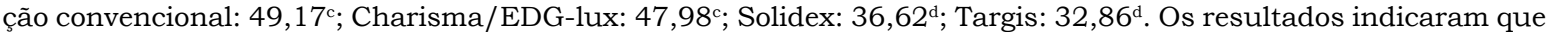
o compósito Z250 polimerizado adicionalmente mostrou os maiores valores de DTS. O compósito Charisma não apresentou diferenças significativas quando foram comparadas diferentes técnicas de polimerização. Compósitos diretos apresentaram maiores valores de DTS que os compósitos indiretos.

DESCRITORES: Resinas compostas; Propriedades fisicas; Resistência à tração.

\section{INTRODUCTION}

An important milestone in the history of modern restorative dentistry was the development of light-cured composite resins for direct procedures ${ }^{1,7,9,14}$. Improvements in composite resin mechanical properties and light curing devices have permitted their use in posterior teeth with greater reliability than was the case some years ago ${ }^{1,3,7,9}$. Shrinkage stress, however, is one of the inherent disadvantages that occur when visible lightactivated resin composites are submitted to light

\footnotetext{
* PhD Students; **PhD, Professor - Department of Restorative Dentistry, School of Dentistry of Piracicaba, State University of Campinas.

*** PhD, Assistant Professor, Department of Statistics and Mathematics, Higher School of Agriculture "Luiz de Queiroz" (ESALQ), University of São Paulo.
} 
Casselli DSM, Worschech CC, Paulillo LAMS, Dias CTS. Diametral tensile strength of composite resins submitted to different activation techniques. Braz Oral Res 2006;20(3):214-8.

polymerization. Direct composites have also been associated with undesirable characteristics such as excessive wear, deficient interproximal contacts, microleakage and postoperative sensitivity ${ }^{1,7,9,12}$.

Indirect systems became popular to overcome these limitations of direct restorations ${ }^{12,13}$. Post-curing of light-cure composite material was introduced more than a decade ago ${ }^{1,6-8,10,13,15}$. Restorations manufactured with light-cured resin composite material were removed from model or tooth and placed in a special curing oven for a period of time. The oven provides heat and light and ensures optimal curing and conversion of the resin ${ }^{6,13,15}$. Specifically, addition of heat may improve physical diametral tensile properties ${ }^{13,15}$, compressive and flexural strengths ${ }^{15}$, wear resistance, hardness ${ }^{13}$, and polymerization conversion ${ }^{6,8}$. Achieving adequate depth of cure of radiation-activated polymers is important to ensure optimal mechanical properties of the restoration ${ }^{1,4,13-14,16}$. Thus, the physical properties of the resin are enhanced and the effects of polymerization shrinkage are minimized ${ }^{10}$.

On the other hand, there are problems related to the chemistry of cured composite, particularly to the degree of conversion and cross-linking den$\operatorname{sity}^{2,11,16}$. It may be influenced by many factors including chemical structure of the monomers, light illumination time and intensity needed to activate polymerization, and filler composition ${ }^{1,14,16}$. Investigation into the effect of post-curing on the properties of dental materials would be beneficial for the development of restorative dental materials.

Filler content, filler particle size and distribution of the filler particles all highly influence the physical and mechanical properties of the composite materials ${ }^{2,4,11,14,16}$. Manufacturers have increased the filler content and reduced the average filler particle size to produce resin-based composite materials for Class II posterior restorations, which need adequate strength and wear resistance to withstand masticatory forces to which they are subjected ${ }^{9,14,16}$.

These posterior resin-based composites have basically the same chemistry and physical characteristics, however the cure conditions still are the most important difference between them.

The purpose of this investigation was to examine the diametral tensile strength of composite resins submitted to different light activation techniques.

\section{MATERIALS AND METHODS}

Four commercially available light-cured composite resin restorative materials, namely, Solidex
(Shofu, Higashiyama-Ku, Kyoto, Japan), Targis (Ivoclar Vivadent Pty Ltd., Noble Park North, Melbourne Victoria, Australia), Charisma (Heraeus-Kulzer, Gonsennheumer, Mainz, Germany) and Filtek Z250 (3M Espe, St. Paul, MN, USA), shade A3, were tested. These materials are described in Table 1.

The materials were handled according to the manufacturer's instructions. Teflon split molds (Cometa S.A., Piracicaba, SP, Brazil) with $3 \mathrm{~mm}$ in depth and $6 \mathrm{~mm}$ in diameter were used to prepare the cylindrical specimens, according to ADA specification \#27, item 5 .

The resins were used in incremental layers, ranging from 1.0 to $1.5 \mathrm{~mm}$ in height, and they were cured according to the experimental groups. Eight specimens were made for each group.

G1: Specimens were made with Solidex resin and each layer was cured for 90 seconds. After that, specimens were heat-light cured for 7 minutes, using an EDG-lux high-intensity xenon photo-curing unit machine (EDG, São Carlos, SP, Brazil). G2: Specimens were made with Targis resin and each layer was cured for 20 seconds (Targis Quick - light curing). After that, specimens were post-cured for 25 minutes, using a special machine (Targis Power - heat-light curing). G3: Charisma composite resin was cured with a light curing unit (Degulux Soft

TABLE 1 - Composition of composite resins evaluated in the present study.

\begin{tabular}{|c|c|c|}
\hline Brand & Manufacturer & Composition \\
\hline Solidex & Shofu & $\begin{array}{l}\text { - } 53 \% \text { inorganic and } \\
\text { ceramic microfila- } \\
\text { ments; } \\
\text { - } 25 \% \text { co-polymers of } \\
\text { multi-functional res- } \\
\text { ins; } \\
\text { - } 22 \% \text { conventional res- } \\
\text { ins / light-initiators }\end{array}$ \\
\hline Targis & Ivoclar & $\begin{array}{l}\text { - Urethane dimethacry- } \\
\text { late; } \\
\text { - Decanediol dymeth- } \\
\text { acrylate Bis-GMA; } \\
\text { - Barium glass, mixed } \\
\text { oxide; } \\
\text { - Silicon Dioxide }\end{array}$ \\
\hline Charisma & Kulzer & $\begin{array}{l}\text { - } 64 \% \text { of filler: Barium } \\
\text { aluminium fluoride } \\
\text { glass; } \\
\text { - Bis-GMA and TEG- } \\
\text { DMA }\end{array}$ \\
\hline$Z 250$ & 3M/Espe & $\begin{array}{l}\text { - Bis-GMA, UDMA and } \\
\text { Bis-EMA; } \\
\text { - } 66 \% \text { of filler: Zirco- } \\
\text { nium/Silica }\end{array}$ \\
\hline
\end{tabular}


Casselli DSM, Worschech CC, Paulillo LAMS, Dias CTS. Diametral tensile strength of composite resins submitted to different activation techniques. Braz Oral Res 2006;20(3):214-8.

Start, Degussa Hills, Hanau, Germany) with a light intensity of 400 to $700 \mathrm{~mW} / \mathrm{cm}^{2}$ for 40 seconds per layer (conventional polymerization). G4: Charisma composite resin was light-cured through conventional polymerization. After that, it was post-cured in an EDG-lux oven, by heat-light activation, during 7 minutes. G5: Charisma composite resin was light-cured through conventional polymerization. After that, it was post-cured using a specific machine for Targis resin activation (Targis Power), during 25 minutes. G6: Z250 composite resin was light-cured through conventional polymerization. G7: Z250 composite resin was light-cured through conventional polymerization. After that, it was post-cured using the special machine EDG-lux during 7 minutes. G8: Z250 composite resin was light-cured through conventional polymerization. After that, it was post-cured using Targis Power during 25 minutes.

The prepared specimens were stored in a lightproof container with artificial saliva at $37^{\circ} \mathrm{C}$ for 1 week. Diametral Tensile Strength (DTS) testing was performed using a Universal Testing Machine (Instron Corporation, Canton, MA) at a crosshead speed of $0.5 \mathrm{~mm} / \mathrm{min}$. Specimens were positioned vertically on the testing machine base and subjected to compressive load until failure. Mean DTS values were expressed in MPa and the data were analyzed by ANOVA, followed by Duncan's test at the 0.05 level of significance.

\section{RESULTS}

The values obtained through DTS testing were subjected to analysis of variance (ANOVA), which revealed significant differences among the experimental groups. In order to document these results, Duncan's test was applied (Table 2).

The Duncan test showed that a major range of DTS values was presented by group $Z 250$ with post-curing using EDG-lux (G7). This group did not show statistical differences in relation to the Z250 resin group which was post-cured with Targis Power (G8). The group Z250 with conventional polymerization (G6) showed smaller values than G7 and G8.

Specimens of Targis resin (G2) showed the smallest values of DTS and did not show differences in relation to the Solidex group (G1). For the Charisma groups, no significant difference was found between the activation modes (Graph 1). These groups showed intermediate DTS values.
TABLE 2 - Mean diametral tensile strength values for the experimental groups $(\mathrm{MPa})$.

\begin{tabular}{l|c|c}
\hline \hline \multicolumn{1}{c|}{ Experimental group } & $\begin{array}{c}\text { Mean } \\
\text { DTS }\end{array}$ & $\begin{array}{c}\text { Statistical } \\
\text { Grouping }\end{array}$ \\
\hline Z250/EDG-lux (G7) & 69.036 & $\mathrm{a}$ \\
\hline Z250/Targis Power (G8) & 68.568 & $\mathrm{a}$ \\
\hline $\begin{array}{l}\text { Z250 (conventional } \\
\text { polymerization) (G6) }\end{array}$ & 60.751 & $\mathrm{~b}$ \\
\hline Charisma/Targis Power (G5) & 52.340 & $\mathrm{c}$ \\
\hline $\begin{array}{l}\text { Charisma (conventional } \\
\text { polymerization) (G3) }\end{array}$ & 49.166 & $\mathrm{c}$ \\
\hline Charisma/EDG-lux (G4) & 47.981 & $\mathrm{c}$ \\
\hline Solidex (G1) & 36.622 & $\mathrm{~d}$ \\
\hline Targis (G2) & 32.862 & $\mathrm{~d}$ \\
\hline \hline
\end{tabular}

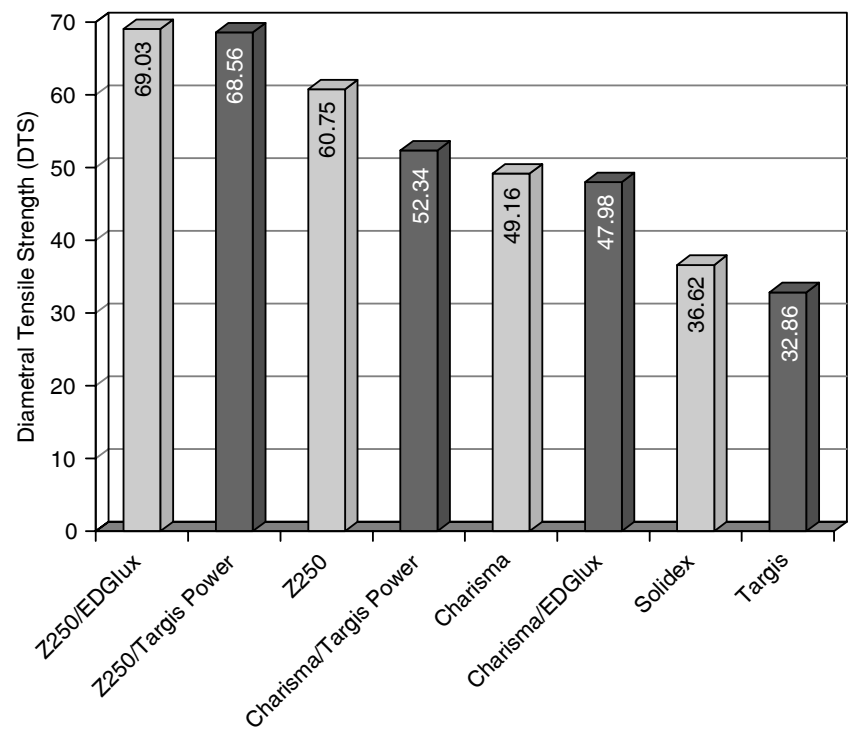

GRAPH 1 - Results of Diametral Tensile Strength (MPa) for the tested materials.

\section{DISCUSSION}

Composite resin polymerization occurs by the conversion of the monomer molecules into a polymer network, accompanied by a closer packing of the molecules, causing contraction in the composite ${ }^{1,2,11}$. Polymerization shrinkage creates stress on the restored tooth that may result in poor marginal integrity, and inadequate durability and longevity in the oral environment ${ }^{9,12}$. These factors are related to the chemistry of dental composites, particularly to the degree of conversion (DC) and the cross-linking density ${ }^{4,12,14,16}$.

DTS is an acceptable and common test for dental composites ${ }^{1,5,13-16}$. The DTS values of the 
Casselli DSM, Worschech CC, Paulillo LAMS, Dias CTS. Diametral tensile strength of composite resins submitted to different activation techniques. Braz Oral Res 2006;20(3):214-8.

composites tested in the present study are in the DTS range of dental composites, 30-55 $\mathrm{MPa}^{16}$. In the present study, the composite DTS values were in the 30 to $70 \mathrm{MPa}$ range, which are acceptable values for composites.

A positive correlation has been demonstrated between the degree of monomer to polymer conversion (DC) and mechanical properties of composites $^{4,8,14,16}$. Degree of monomer conversion (DC) and cross-linking density in composites are influenced by many factors, including monomeric composition, light intensity, curing time and filler content in the resin matrix ${ }^{3,4,8,11,14,16}$.

The highest mean of DTS was observed for post-cured $Z 250$ groups, and the lowest mean was observed for indirect composites (Targis and Solidex), which demonstrates the influence of composite components on DTS. Monomeric composition affects the degree of conversion of dental composites and the quality of the restoration ${ }^{3,4,14,16}$. The composition of Filtek Z250 includes Bis-GMA, Bis-EMA and UDMA. Bis-EMA and UDMA are molecules of higher molecular weight with the best properties of visible light diffusion ${ }^{14}$. The replacement of Bis-GMA or TEGDMA by UDMA results in an improvement of mechanical properties (tensile and flexure strength) $)^{2,11,14}$. UDMA has been reported to have lower viscosity and the flexibility of urethane linkage, which may improve the toughness of resin composites containing this monomer. Besides, there are indications that higher degrees of conversion are obtained with urethane dimethacrylates when compared with that of Bis-GMA ${ }^{2,11,14}$. Beyond a possible effect of the degree of conversion, the increase in tensile strength may be associated with the ability of urethane linkage to form hydrogen bonds in the copolymer, which presumably results in a restricted sliding of polymer segments in relation to each other ${ }^{2,11,14}$.

Post-curing is important as it can increase the degree of conversion and affect mechanical properties positively $8,10,12,13,15,16$. The results of the present study demonstrated that post curing methods improved the mechanical properties of direct composite resins. In the $Z 250$ groups, it was possible to note that post-curing through heat or light treatment was able to improve the mechanical results in DTS tests. This could be explained by the fact that this composite resin has UDMA and BIS-EMA in its formulation, along with Bis-GMA, and so the conversion degree would be improved with light or heat treatment.

Charisma is a micro hybrid composite with $64 \%$ in weight of filler content. It presents TEGDMA/Bis-GMA as its monomeric composition. The Charisma groups showed intermediate DTS values, and it was observed that post-curing was not able to improve their mechanical results in DTS tests. This might be explained by the fact that this composite resin has TEGDMA and Bis-GMA in its formulation, along with traditional dimethacrylate. These monomers have shown the highest conversion degree with a conventional polymerization technique. Therefore, post-curing treatment shows the same results as conventional treatment.

An increase in filler content in the resin matrix improves the mechanical properties of dental composites, such as: compressive and diametral tensile strengths ${ }^{3,4,15,16}$, abrasion resistance, coefficient of thermal expansion and modulus of elasticity ${ }^{11,15,16}$. Filtek Z250, with $66 \%$ of filler content showed the highest values of DTS, followed by Charisma, with $64 \%$ of filler content, Solidex, with 53\%, and Targis with approximately $50 \%$ of filler content.

In spite of presenting dimethacrylate in their formulations, Solidex and Targis have shown low volumes of filler, and this fact may interfere in DTS ${ }^{4,14,16}$. In the present study, Targis and Solidex were used as controls for direct resin application with additional polymerization. It was shown that Charisma and Z250 might be used in indirect techniques and would show high DTS values. However, only the DTS test is not sufficient to determine the indication of a restorative material. Therefore, new studies are necessary to confirm the possibility of using direct resins in indirect resin techniques.

\section{CONCLUSIONS}

Direct composite resins presented higher DTS values than indirect resins. The results suggested that Charisma and Filtek Z250 might be used in indirect techniques with post-curing polymerization. The composite restorative materials presented different DTS values, which shows that filler content and monomer composition affect the properties of restorations. 
Casselli DSM, Worschech CC, Paulillo LAMS, Dias CTS. Diametral tensile strength of composite resins submitted to different activation techniques. Braz Oral Res 2006;20(3):214-8.

\section{REFERENCES}

1. Aguiar FHB, Braceiro ATB, Ambrosano GMB, Lovadino JR. Hardness and diametral tensile strength of a hybrid composite resin polymerized with different modes and immersed in ethanol or distilled water media. Dent Mater 2005;21:1098-103.

2. Asmussen E, Peutzfeldt A. Influence of UEDMA BisGMA and TEGDMA on selected mechanical properties of experimental resin composites. Dent Mater 1998;14(1):51-6.

3. Chung KH. The relationship between composition and properties of posterior resin composites. J Dent Res 1990;69(3):852-6.

4. Chung KH, Greener EH. Correlation between degree of conversion, filler concentration and mechanical properties of posterior composite resins. J Oral Rehabil 1990;17(5):48794.

5. Council On Dental Materials And Devices. New American Dental Association Specification $\mathrm{N}^{\circ} 27$ for direct filling resins. J Am Dent Assoc 1977;94(6):1191-4.

6. Ferracane JL, Hopkin JK, Condon JR. Properties of heat-treated composites after aging in water. Dent Mater $1995 ; 11(6): 354-8$

7. Hammesfahr PD, O'Connor MT, Wang X. Light-curing technology: past, present, and future. Compendium 2002;23(9 Suppl 1):18-24.

8. Lee SY, Lee CS. The difference in degree of conversion between light-polymerized and additional heat-polymerized composites. Oper Dent 1996;21:213-7.
9. Manhart J, Chen HY, Hickel R. The suitability of packable resin-based composites for posterior restorations. J Am Dent Assoc 2001;132(5):639-45.

10. Marais JT, Dannheimer MF, Oosthuizen MP, Booyse A. The effect of post-curing on Vickers Hardness of four lightcure resin composite materials. SADJ 1999;54(3):123-5.

11. Peutzfeldt A. Resin composites in dentistry: the monomer systems. Eur J Oral Sci 1997;105(2):97-116.

12. Soares CJ, Celiberto L, Dechichi P, Fonseca RB, Martins LRM. Marginal integrity and microleakage of Direct and Indirect Composite Inlays: SEM and stereomicroscopic evaluation. Braz Oral Res 2005;19(4):295-301.

13. Soares CJ, Pizi EC, Fonseca RB, Martins LRM. Mechanical properties of light-cured composites polymerized with several additional post-curing methods. Oper Dent 2005;30(3):389-94.

14. Tolosa MCCG, Paulillo LAMS, Giannini M, Santos AJS, Dias CTS. Influence of composite restorative materials and light-curing units on diametrical tensile strength. Braz Oral Res 2005;19(2):123-6.

15. Wendt SL Jr. The effect of heat used as secondary cure upon the physical properties of three composite resins. I. Diametral tensile strength, compressive strength, and marginal dimensional stability. Quintessence Int $1987 ; 18(4): 265-71$.

16. Zandinejad AA, Atai M, Pahlevan A. The effect of ceramic and porous fillers on the mechanical properties of experimental dental composites. Dent Mater 2006;22(4):382-7. 